\title{
Preface to International Symposium of Catalysis for Clean Energy and Sustainable Chemistry (CCESC2018)
}

\author{
José F. Cambra ${ }^{1}$ - V. Laura Barrio ${ }^{1} \cdot$ Pedro L. Arias ${ }^{1} \cdot$ Jesús Requies $^{1}$
}

Published online: 18 June 2019

(c) Springer Science+Business Media, LLC, part of Springer Nature 2019

Nowadays, sustainability is not just a word or a fashion: it is a goal, a need. Even more, sustainability represents the future.

In an attempt to collaborate in the preservation of the human race, the International Symposium on the Catalysis for Clean Energy and Sustainable Chemistry is fully devoted to the above-mentioned topic. This Symposium was launched in 2008 to celebrate the 60th birthday of Professor García-Fierro. Since then, four editions have been held, three in Madrid (Spain) and the last one in the School of Engineering of Bilbao (Spain). This volume of Topics in Catalysis is dedicated to this last edition (2018).

The objective of the Organizing Committee of this International Symposium was to organize a worldwide encounter among scientists and industrialists with interest in the technological aspects of catalysis application to the sustainable development.

This symposium has helped in the review of the present state of the art of these catalytic technologies and in discussions of the possible future directions of their evolution, and of course, how they can positively impact on the development of our societies.

The range of the topics covered in the research fields in the Congress is remarkable, from the production of new green energy vectors and fuel substitutes and additives to green chemicals and $\mathrm{CO}_{2}$ utilization.

In short, the presentations were classified into the following areas of research: (1) biosyngas production and transformation (FTS, Methanol, DME); (2) biofuels from gasification and pyrolysis; (3) high value-added products from lignocellulose, algae and waste oils; (4) biorefinery processes; (5) novel processes; (6) photocatalysis and heterogeneous catalysis for water and air treatment; (7) $\mathrm{CO}_{2}$

José F. Cambra

jose.cambra@ehu.eus

1 Escuela de Ingeniería de Bilbao, Plaza Ingeniero Torres Quevedo 1, 48013 Bilbao, Spain as raw material; (8) hydrogen production; (9) fuel cells and electrocatalysis; (10) $\mathrm{H}_{2}$ storage; and (11) power to gas.

To give an idea of the impact of this Symposium, some figures follow. More than 100 researchers, from senior to doctorate levels, attended the Symposium, coming from 15 different countries: Germany, Australia, Belgium, Denmark, Spain, Finland, France, the Netherlands, Italy, Poland, Portugal, the United Kingdom, Russia, Switzerland and the United States of America.

The quality and high level of knowledge of the invited speakers was another remarkable success. Six plenary lectures were offered during this three-day congress by Regina Palkovits (RWTH Aachen University, Germany), Javier Pérez-Ramírez (ETH Zurich, Switzerland), Graham Hutchings (Cardiff University, United Kingdom), Pablo Beato (Haldor Topsoe, Denmark), Luigi Crema (Vice-Chair for Energy to Hydrogen, Hydrogen Europe), and Jaime Martín Juez (Repsol, Spain).

At the end of the Symposium, two special awards were given to the best oral and poster presentations by young scientists. This special event was dedicated to the loving memory of our colleague in the School of Engineering of Bilbao, Prof. Belén Güémez Bilbao. The winners were María José Ginés-Molina (University of Málaga) for the best oral presentation and Max Schumann (Technical University of Denmark) for the best poster presentation.

Thus, taking into account all the aforementioned background, the present issue of Topics in Catalysis, devoted to this Fourth International Symposium on the Catalysis for Clean Energy and Sustainable Chemistry, is highly recommended reading.

The reader will find in the present issue the very best communications presented during this 3 days Congress, sorted by topics. The first four papers are dedicated to hydrogen production from renewable electricity, water splitting, reforming of green hydrogen sources and waste utilization. The another four works focus on hydrogen storage are presented, two of them relating to storing hydrogen in the form 
of formic acid, and the remaining share the field of storage with $\mathrm{CO}_{2}$ utilization and power to gas areas, i.e. methane production from renewable hydrogen and $\mathrm{CO}_{2}$. Next, two papers fall within the scope of biofuels, covering the production of oxygenated compounds obtained from biomass that can be used as fuel substitutes or additives. Finally, three papers study the production of chemicals from biomass derivatives, such as furfural, glucose or levulinic acid.

We would like to thank the collaboration of Topics in Catalysis. We would also like to thank our sponsors: IDOM (Gold), Iberfluid, Iesmat, PID Eng\&Tech and SENER (Silver), Nortegas (Bronze), and Air Liquide, SUL and Thermofisher Scientific (Others). In addition, we would like to express our gratitude to the University of the Basque
Country (UPV/EHU) for the venue, and with special mention to the staff of the School of Engineering, for their help and assistance during the Symposium.

Finally, we would like to acknowledge the support of the staff of Topics in Catalysis for making this issue possible. Special thanks go to Prof. Dr. Hans-Joachim Freund who allowed the publication of this issue, as well as Dr. Charlotte Hollingworth, Ms. Anitha Kamaraj, and Mr. Matthew Smyllie for technical assistance. We want also thank the reviewers for their effort, as well as all authors for their patient and enthusiastic response, and all congress attendants for their active involvement and participation in this congress. 